\title{
A s conseqüências das novas leis de segurança sobre a comunicação local e global*
}

\author{
Christiano German ${ }^{* *}$
}

\begin{abstract}
Resumo: Pretende-se apontar e examinar as novas medidas de segurança anti-terror adbtadas nos Estados Unidos e na Europa.A eficácia das novas leis de segurança após o "11 de setembro" e suas consequîencias para a comunicação eletrônica. O uso de sistemas de espionagem e os efeitos dos ataques terroristas sobre 0 impulso do espírito civilizatório do Ocidente. O texto discute ainda as vantagens e desvantagens das "Medidas Patrióticas" e que consideraçães podem ser feitas sobre a formação de um estado de vigilância e a desmontagem dos direitos de liberdade e de cidadania.
\end{abstract}

Palavras-chave: leis de segurança antiterror; vigilância e direito de sigilo na Intemet; terrorismo.

Introdução

Os pressupostos e as condições de segurança interna e externa modificaram-se fundamentalmente após os ataques terroristas de 11 de setembro. Na A lemanha e nos EUA, foram aprovadas leis complementares que ampliam e fortalecem significativamente a competência dos serviços públicos de segurança. A lém disso, o FBI estabeleceu uma nova lista de prioridades, em face também dos sérios desgastes sofridos pelas autoridades públicas e da CIA. Os três pontos prioritários são: 1) proteger os Estados U nidos de ataques terroristas; 2) proteger os Estados Unidos de operações de inteligência estrangeira e espionagem, e 3) proteger os Estados Unidos de ataques cibernéticos e de crimes de alta tecnologia (M arkus, 2002, p. 8). 0 último ponto

\footnotetext{
* Tradução de Marcelo Gross Villanova.

** Professor de Ciência Política e Relações Internacionais na Universidade Católica de Eichstaett e de Política Européia na Universidade Técnica de Braunschweig - RFA. Sócio fundador do Instituto Brasileiro de Política e Direito da Informática (IBDI), em Recife (PE). E-mail: dr.german@ web.de.
}

revela que a utilização criminosa da tecnologia de informática avançou para a terceira colocação entre as maiores ameaças (German, 2000, p. 113-136).

Enquanto para a população da Europa O cidental pós-Segunda Guerra tornou-se natural viver em uma sociedade aberta e de democracia liberal, muitos países latino-americanos podem ainda lembrar-se dos regimes autoritários e do penoso processo de democratização. Hoje, a civilização ocidental vê-se confrontada com extremistas e suicidas em luta por um Estado religioso islâmico, aos quais a história, a concepção e a causa da democracia são estranhas. Esses fundamentalistas religiosos rejeitam os val ores predominantes do 0 cidente, da liberdade individual e de poder conformá-la segundo os seus próprios valores na sua vida pessoal e religiosa (Herzinger, 2002, p. 3-6, 4). A qui figuram especial mente os Estados U nidos, com seu al tamente valorizado princípio de liberdade religiosa, em completa contradição com uma teocracia que siga a vontade de A lá e as normas do Alcorão. Sob a perspectiva da filosofia do direito, o professor de direito alemão Georg 
J ellinek salientou que o mais importante impulso na formação moderna dos direitos humanos remonta à reivindicação da liberdade de consciência e da profissão de fé (Schnur, 1964). A tese pioneira de Georg J ellinek diz que o inato e inalienável direito sagrado do indivíduo, fortal ecido pela lei, teria uma origem religiosa e não política (Henning, 1988, p. 1104-1118, 1116). Sob esse ponto de vista, cada limitação dos direitos de liberdade seria uma perda das conquistas do espírito civilizatório do O cidente.

\section{As novas leis de segurança nos EUA}

\subsection{Panorama do novo ordenamento}

O Congresso americano aprovou o US Patriot A ct (A to Patriótico A mericano), que ampliou as leis antiterror existentes, sob o impacto dos ataques de 11 de setembro (cf. Funk, 2001, p. 63-70). A pós cinco semanas de negociações, as novas determinações foram aprovadas em 5 de outubro de 2001 e assinadas pelo presidente $\mathrm{G}$ eorge W. B ush um dia depois. N enhuma lei até então havia tramitado tão rapidamente na história do Congresso americano. ${ }^{1}$ Enquanto a União Européia ainda tentava, cautelosamente, compreender melhor o tema, o governo americano e o alemão aproveitaram-se da situação de choque e de insegurança general izada para impor dispositivos de segurança interna sem longos debates. Críticas públicas foram manifestadas apenas pelos liberais do Partido Democrático Liberal, na A lemanha, e pel o senador democrata R ussell Feingold, nos Estados U nidos.

0 senador de Wisconsin advertiu que a guerra contra o terror estará perdida, "sem darse um tiro sequer", quando forem sacrificadas as liberdades dos cidadãos americanos.

Conforme 0 efeito pretendido pela nova legislação, poder-se-ia apurar e reunir todos os dados sobre um cidadão americano assim que ele se sentasse em um avião que estivesse sob suspeita de ataque terrorista. O utros deixaramse convencer pela cláusula sunset (pôr-do-sol), que prevê a perda da validade do US Patriot A ct em quatro anos - no dia 31 de dezembro de

1. 0 texto pode ser encontrado, entre outros, em: http:// personalinfomediary.com/USA PATRIOTACT_Text.htm.
2005 - , vedada sua prorrogação ou reedição pelo Congresso. Todavia, os resultados alcançados pelas averiguações poderão ser utilizados após esse período.

Podemos resumir aqui apenas as determinações mais notáveis do U S Patriot $A$ ct. $^{2}$ D aqui por diante, 0 apoio a terroristas será punido como crime federal, com penas mais el evadas. Foram incluídas previsões contra o bioterrorismo, medidas essencialmente mais rigorosas contra imigrantes suspeitos de estarem envolvidos em atos terroristas, e controles mais amplos sobre a suspeita de lavagem de dinheiro e os bancos de fachada (shell banks), que não tenham ligações regulares com instituições bancárias. Foi ampliada igualmente a competência dos serviços de informação sobre a vigilância de pessoas, bem como a permuta dos resultados apurados entre as diversas agências. A lém disso, a nova lei permite a revista domiciliar sem 0 mandato de busca e apreensão, ainda que na ausência do proprietário ou locatário.

A pós oito meses de preparação, Georg W. Bush dirigiu ao Congresso, em julho de 2002, outras cem páginas de uma extensa concepção de segurança antiterror. A o mesmo tempo, o Congresso formou, contra a vontade da Casa Branca, uma comissão independente de investigação para ocupar-se das falhas do serviço secreto que antecederam o dia 11 de setembro. ${ }^{3} \mathrm{No}$ centro das estratégias de segurança, está a formação de um M inistério para a Proteção da Pátria (Department of Homeland Security), com quase 170 mil funcionários, recrutados entre o grande número de colaboradores existentes, o que não deve acarretar um custo adicional. Os novos "superfuncionários" devem dar segurança às fronteiras; reagir, rápida e amplamente, em caso de catástrofes iminentes ou urgências, e também desenvolver métodos científicos para descobrir armas de extermínio em massa, sejam elas biológicas, químicas ou nucleares (cf. $\mathrm{K}$ oydl, 2002a, p. 5). A demais, estão previstas inúmeras

2. Cf.: Senate passes antiterrorism measure, granting expanded powers to government, a closer look. The New York Times, 26/10/2001.

3. Cf. sobre: Noch einmal 28,9 Milliarden Dollar für die Terrorbekämpfung. In: F rankfurter Allgemeine Zeitung, 26 de julho de 2002, 2. 
medidas para a unificação da regulamentação e das leis das unidades federativas, além de uma ampliação dos poderes constitucionais do presidente (cf. K oydl, 2002b, p. 8).

\subsection{As estratégias de segurança na prática}

Segundo prometeu Georg W. Bush, o governo empregará as leis com toda a firmeza de uma "nação em guerra". O ministro da J ustiça, J ohn A shcroft, informou que todo aquele que for suspeito de participar de atividades terroristas será detido e mantido preso por todo o tempo que for necessário. E se, por exemplo, 0 visto de alguém houver expirado, ainda que por apenas um dia, a expulsão será imediata.

Nos Estados U nidos, a detenção de "combatentes inimigos" (enemy combatant) e de "testemunhas relevantes" (material witnesses) está incluída na controvertida questão legal do combate ao terrorismo. A té agora, há dois casos conhecidos em que cidadãos americanos foram declarados como "combatentes inimigos" sob ordens do presidente em seu papel de comandante-chefe das forças armadas. A qui, trata-se de um tipo de prisioneiro de guerra sem embasamento legal ou constitucional, que pode ser transferido ao M inistério da D efesa sem direito a qual quer consulta jurídica. Essa classificação jurídica, sem definição precisa, foi anteriormente aplicada a uma única pessoa: um americanoalemão, sabotador nazista, no ano de 1942, época da Segunda Guerra (cf. K oydl, 2002c, p. 3).

No caso dos cidadãos americanos enquadrados como "combatentes inimigos", tem-se um exempl o típico das desigual dades de tratamento nos Estados U nidos. 0 primeiro, um "americano talibã", J ohn Walker Lindh - um branco de 21 anos, filho de um advogado de família abastada e representado por um advogado renomado -, pode ser condenado a pena de 20 anos sob a forma de um "acordo negociado" (plea bargain), isto é, um acordo jurídico firmado entre defesa e promotoria (cf. Koyld, 2002d, p. 8). 0 segundo, Jose Padilla, um porto-riquenho convertido ao islã, provém, em contraste, de uma família de poucas posses. Padilla, de 31 anos de idade, pretensamente pretendia detonar uma bomba de contaminação radioativa no Estados U nidos e está preso numa cela em uma base militar, por tempo indeterminado e sem acusação formal. Isto, de acordo com sua advogada, com base em denúncias de fontes desconhecidas, cuja confiabilidade e credibilidade são incertas. Certo é apenas que Padilla realizara "estudos dirigidos" em páginas da Internet, que se ocupam de bombas radioativas (dirty bombs). No começo do mês de agosto de 2002, um juiz de N ova Y ork exigiu do governo americano que fosse feita uma declaração completa sobre as razões da detenção para investigação do suspeito, preso há dois meses. ${ }^{4}$

A lém disso, um tribunal federal decidiu no mesmo mês, por requerimento de grupos de direitos humanos, que a detenção secreta e a prisão sem mandato jurídico contradizem os princípios da democracia. Sob o fundamento da "Iei da liberdade de informação" (Free Information A ct), foi solicitada a divul gação pelo governo dos nomes dos detidos. ${ }^{5}$

Do ponto de vista legal, não fica nada clara a situação de mais de 500 não-americanos de mais de 30 países (Inglaterra, A ustrália e K uwait, entre outros) detidos na base naval da B aía de Guantánamo, em Cuba. A estes, não será reconhecido o status de presos de guerra, nem será instaurado qualquer processo contra eles. 0 governo Bush escolheu uma área militar fora dos Estados Unidos claramente com 0 propósito de aproveitar-se de um vácuo jurídico. Nesse sentido, a juíza federal Colleen K ollarKotelly afirmou, no início de agosto de 2002, que, no caso de uma base militar situada fora dos Estados U nidos, tribunais federais não podem decidir se os prisioneiros que lá se encontram teriam sido detidos arbitrariamente. Com isto, escapa-se de qualquer apelação ao direito americano ou a um processo perante um tribunal americano. Os assim enquadrados como perigosos terroristas do AI-Q aeda ou Talibã devem assim permanecer até "o final dos combates", o que também será determinado por Washington. A qui, aposta-se no fator tempo para obter dos desmoralizados prisioneiros a

\footnotetext{
4. Cf. AP/A FP. G efangene scheitern mit K lage. In: Süddeutsche Zeitung, 2 de agosto de 2002, p. 7.

5. Cf. Dpa. USA müssen Verdächtigen freilassen. In: $S Z, 2$ de maio de 2002, p. 11 Cf. AFP/A P. USA müssen Namen von Terror-Verdächtigen nennen. In: SZ, 5 de agosto de 2002, p. 6.
} 
maior quantidade possível de informações sobre as estruturas terroristas.

N o entanto, esses métodos contrapõem-se a todos os princípios básicos do Estado de direito e do direito internacional. Somente após numerosos protestos internacionais dos movimentos de direitos humanos, as condições da prisão da Baía de Guantánamo foram minimamente melhoradas. Os Estados U nidos rejeitam, contudo, um protocolo suplementar para internacionalizar a Convenção A ntitortura, que prevê controles de presos desse tipo. Em torno a essa rejeição, formou-se uma rara comunhão de interesses, que inclui (além dos EUA) países como Irã, Líbia e Cuba ${ }^{6}$ - nações que, na doutrina da política externa dos Estados U nidos, são tidas como "Estados malévolos" (rogue states) ou, na linguagem dos diplomatas, "Estados que ameaçam a Paz e a Segurança Internacionais" (States Threatening International Peace and Security - Stips). Na linguagem popular do presidente americano, eles são conhecidos como o "eixo do mal".

\section{A situação na Alemanha}

\subsection{0 pacote antiterror}

Os ataques terroristas na A mérica, em 2001, tiveram também conseqüências para a política interna e externa da A lemanha. J untamente com uma nova orientação para a utilização das forças armadas no estrangeiro, com os dois pacotes antiterror e mais de uma centena de alterações nas leis, foi concedida primazia à segurança sobre a liberdade. ${ }^{7}$ A seguir, será apresentado apenas um breve panorama sobre as novas determinações e, subseqüentemente, no que diz respeito à busca policial sistemática e a perseguição de membros de organizações terroristas estrangeiras, serão aprofundados dois campos de problemas especiais. ${ }^{8}$

E $m$ primeiro lugar, há nas novas regulamentações uma mudança quanto ao direito de

6. Cf. UI. Kubanische Verhältnisse. In: SZ, 2 de agosto de 2002, p. 4

7. Para encontrar um completo quadro geral, ver: http:// text.bundesregierung.de/frameset/ixnavitext.jsp?nodel $D=$ 6587

8. Cf. http://text.bundesregierung.de/frameset/ixnavitext. jsp?nodel $D=7922$ \#abschnitt17. reunião religiosa. De agora em diante, podem ser proibidas associações extremistas, que se disfarçam como religião ou como comunidade ideológica. Com o Pacote A ntiterror $\mathrm{II}$, de $1^{\circ}$ de janeiro de 2002, muitas novas leis de segurança, bem como regulamentações do direito dos estrangeiros, foram ajustadas. A lém disso, foram modificadas as leis sobre atividades de proteção das frontei ras territoriais e serviço de inteligência.

U m dos objetivos da luta contra o terrorismo é também evitar a entrada de terroristas no território federal. A o mesmo tempo, as leis devem proporcionar o cumprimento de novas medidas de segurança, de modo que terroristas encontrados em território alemão possam ser rapidamente identificados e suas atividades impedidas. Como se sabe, alguns agentes terroristas estudaram e viveram na A lemanha antes dos atentados. A s novas leis devem futuramente tornar impossível a estada na A lemanha de tais "células dormentes" (sleepers).

Um primeiro resultado do M inistério do Interior mostra que ambos os pacotes antiterror trouxeram grandes avanços quanto ao acesso a informações por parte da polícia, bem como melhorias quanto à troca de dados entre a polícia e o serviço secreto (cf. K lingst, 2002, p. 10). Internacional mente, A lemanha e França continuam tendo significativos problemas com os EUA quanto aos esforços em torno de convênios internacionais sobre assistência judicial. Pois, contrariando o padrão europeu de Estado de direito, nem sempre são dadas garantias a um processo justo, à proteção de dados, à exclusão da pena de morte, entre outros. ${ }^{9}$

\subsection{A implementação das leis de segurança}

A pós os ataques nos EUA, as autoridades alemãs reagiram rapidamente. U ma semana depois dos ataques de 11 de setembro, os secretários estaduais aprovaram, pela prim ira vez, uma busca policial sistemática preven va (Rasterfahndung) em todo o território nacio ral, com o propósi to de encontrar "células dorm entes" islâmicas, terroristas potenciais. A busca policial sistemática - hoje realizada por

9. Cf. SZ-Interview mit der Bundesjustizministerin In: Süddeutsche Zeitung, 7 de março de 2002, p. 11. 
computador - teve a sua origem no tempo do terrorismo das B rigadas Vermel has, organização alemã de extrema esquerda da década de 70 . Nos Estados Unidos, não existe esse sistema de busca policial sistemática. As autoridades americanas concentram-se em criar condições especiais de controle sobre estrangeiros ou "residentes alienígenas" (alien residents).

A pesar do levantamento de cerca de seis milhões de dados, não foi encontrado nenhum terrorista, apenas árabes fraudadores da previdência social. Nesses casos, os métodos de busca foram declarados ilegítimos, em parte ou integralmente, pelos tribunais de Berlim, Hessen e Nordrhein-Westfalen, pois a lei de busca policial sistemática exige que haja " perigo iminente para a estabilidade ou segurança da União, dos estados federados ou da vida, do corpo e da liberdade de al guém". Em nenhum momento, contudo, foi este o caso (cf. Bittner, 2002, p. 2).

Enquanto, por um lado, a busca policial sistemática é rejeitada em razão da proteção de dados, por outro, pondera-se que a proteção de dados ef etivamente serve como proteção para os terroristas. Spiros Simitis, o pai do sistema alemão de proteção de dados, avalia que tais argumentos são tão-somente um pretexto ou uma desculpa. Sua convicção é de que há, atualmente, possibilidades legais de elaborar um perfil de atuação de suspeitos, o que poderia não funcionar nos seguintes casos: 1) por falta de esforço dos órgãos competentes na busca de dados corretos em tempo hábil, e 2) por incapacidade, desorganização ou falta de equipamento adequado para que os órgãos competentes pudessem tiram proveito dos dados. Em resumo, os serviços de informação alemães teriam muito pouco a fazer com dispositivos legais. A proteção de dados não seria impedimento para as investigações. M as, sim, levaria o Estado (e todos aqueles que participam de uma investigação) a deter-se em certas regras concernentes à manipulação de informações pessoais, precisamente para a proteção do cidadão comum (cf. K lingst, 2001, p. 5).

N esse contexto, houve uma notável advertência de parte da ex-presidente do Supremo Tribunal Federal Constitucional alemão, em maio de 2002. Por ocasião do $53^{\circ}$ Dia do A dvogado,
Jutta Limbach advertiu quanto ao perigo de "uma ampla política de segurança interna". Segundo ela, o cidadão comum não deve sentir pavor do poder do Estado. A diversidade de opinião eo engajamento político, próprios de uma democracia viva, ficam ameaçados de perderse, "se o Estado se atrever a perseguir sistemática e minuciosamente seus dados e atividades eletrônicas". Ela referia-se às zonas cinzentas na transição entre Estado de direi to e um Estado de defesa preventiva (Präventionsstaat) (cf. Kerscher, 2002, p. 5).

A professora criticou especialmente a busca policial sistemática antes descrita. U ma busca formulada obscuramente, com características como "jovem do sexo masculino, de fé muçulmana, formação técnica e viajante contumaz", usurparia o direito de proteção de dados de um grande número de pessoas atingidas. U ma busca policial sistemática assim poderia manchar reputações e humilhar pessoas. Conforme resultados de uma pesquisa norteamericana, a sra. Limbach chamou a atenção para o fato de que um importante el emento para a disposição ao terrorismo (mais até do que a pobreza e o analfabetismo) é, justamente, a humilhação. É verdade que o terrorismo não tem justificação, embora tenha causas. D essa maneira, a busca policial sistemática pode, em lugar de revelar células dormentes, produzir inimigos. U ma comparação com os motivos dos atentados suicidas de palestinos em Israel confirma essa avaliação, a par de outros aspectos como o ódio ou ainda os al tos donativos para a família do falecido (recebidos, por exemplo, do Iraque). Um pouco antes do atentado, os terroristas presos, quando perguntados, al egaram três motivos: humilhação, humilhação e, novamente, humilhação. Por essa razão, o grupo radical islâmico Hamas dispõe de mais voluntários a atentados suicidas do que de explosivos (cf. Flottau, 2002, p. 2).

Um novo problema na política de segurança alemã deu-se especialmente com a ampliação das disposições no parágrafo $129 \mathrm{~b}$ do Pacote A ntiterror I. A nova prescrição possi bilita também processar penalmente colaboradores de grupo terrorista, ainda que este não exista na A lemanha. As conseqüências são amplas e, juridicamente, em parte controversas. A cima de tudo, a questão 
da definição dos termos "terrorismo" e "luta por liberdade" é complexa, como de resto também o é nos Estados Unidos. A decisão sobre quais grupos estrangeiros são terroristas e quais grupos são parte de uma resistência legítima contra um sistema injusto encontra-se na Procuradoria Geral da República. Os críticos ponderaram que, também nisto, os interesses da política exterior alemã desempenharão um papel importante (cf. Pranti, 2002, p. 4).

A s conseqüências do parágrafo $129 \mathrm{~b}$ para a política interna podem ser, essencialmente, ainda mais problemáticas. A té agora, a A lemanha tinha sido para muitos grupos estrangeiros islâmicos fundamental istas um lugar de refúgio e tranqüilidade. Os inúmeros benefícios ligados a isto não deveriam ser desperdiçados devido às ações de militantes. Tais grupos já eram bem conhecidos pela polícia e pelo serviço de proteção constitucional, assim como suas "organizações de origem" em suas respectivas pátrias. Para essas organizações radicais, a A lemanha, graças à sua política externa equilibrada, não figurava como país hostil ou alvo principal. Com as novas leis de segurança, essa forma de coexistência pacífica alterou-se de forma imprevisível. ${ }^{10}$

3 As conseqüências da política de segurança sobre a comunicação local e global

\subsection{Os novos métodos de controle}

A par dos aspectos ambival entes das novas políticas de segurança dos EU A e da A lemanha já enumerados, o uso conspirativo das tecnologias e dos espaços virtuais no mundo dirigido por computadores cria outros problemas. Como atesta a terceira prioridade da nova lista do $\mathrm{FBI}$, os perigos aumentaram dramaticamente com a utilização da Internet como estrutura de informação e comunicação para o planejamento e execução de crimes. Os terroristas, assim como o crime organizado, trabal ham com tecnologias e meios muito avançados, enquanto as leis dos

10. Com respeito aos fatos, sem as conclusões finais, cf. Pfahl-Traughber. A rmin: Islamismus in der Bundesrepublik D eutschland. Ursachen, Organisation, G efahrenpotential. In: Aus Politik und Zeitgeschichte, B 51/2001, 14 de dezembro de 2001, p. 43-53, 52.
Estados Unidos são do tempo do telefone analógico.

0 Patriot A ct contém, portanto, novas e especiais determinações. A lei simplifica as medidas de controle, como a escuta telefônica e a observação de atividades de suspeitos na Internet pelo $\mathrm{FBI}$ e por outros serviços de informação. A ntes, os investigadores precisavam pedir uma autorização judicial para cada linha tel efônica. A gora, várias linhas tel efônicas utilizadas por suspeitos podem ser espionadas. É permitido aos investigadores obter endereços de e-mail e mesmo acompanhar o momento exato em que ocorre a comunicação el etrônica entre suspeitos. A comunicação eletrônica é tratada como a comunicação telefônica. 0 conteúdo e a duração dessas comunicações podem ser utilizados contra os suspeitos. A autorização judicial não émais necessária para tais vigilâncias de dados. A partir da ampliação da lista de abrangência do conceito de terrorismo, podem ser aí incluídas as atividades de hackers e crakers. Quando um computador no exterior for obstruído ou paralisado e, com isso, for atingido "o comércio entre os estados ou exterior, e mesmo a comunicação nos Estados Unidos", isso será considerado como atividade terrorista e perseguido como tal.

Contudo, logo após os ataques terroristas, o FBI pôde reagir rapidamente, mesmo sem as novas leis de segurança. $E$, assim, começou a instalar o sistema de vigilância DCS-1000 (também chamado de Carnivore) nos provedores de Internet americanos. 0 sistema pode gravar apenas certos dados (armazenados em "recipientes lacrados" no computador do provedor), que correspondam a critérios juridicamente estabelecidos e mediante permissão judicial. 0 dispositivo classifica o tráfico de dados a partir de certas palavras-chave. Parte essencial do software do FBI é a função Dragon Suite, que pode reunir e montar mensagens fracionadas. Esse programa pode, ainda, seguir os rastros de um internauta e mostrar no monitor do FBI as páginas da Internet visitadas por ele. 0 Carnivore conta com a peculiaridade de ser invisível para qualquer internauta (cf. Hürter, 2002, p. V 2/14). M as o Carnivore vem sendo criticado pelas organizações americanas de defesa dos direitos do cidadão como um 
instrumento de vigilância inadmissível. Políticos que defendem os direitos do cidadão em Washington têm constantemente procurado obrigar o governo a manter um controle mais forte sobre essas investigações do FBI na Internet (cf. Borchers, 2001, p. 14).

Também na A lemanha, as novas leis de segurança permitem, de acordo com um dispositivo legal, a interceptação de e-mails visados (cf. B ürgerrechte \& Polizei, 2002). No que concerne à vigilância sobre e-mails e atividades na Internet, a Alemanha tem, entretanto, se esforçado por conseguir uma solução comum com a U nião E uropéia. N esse sentido, foi aprovada em B ruxelas a Instrução de Utilização de Dados Relativos a Pessoas, que permite que sejam arquivados, em caso de ameaça à segurança interna, todos os dados necessários de e-mails, atividades na I nternet, números de cartões de crédito e de contas, e também que seja apontada a localização geográfica dos utilizadores de telefones celulares. Desde há dois anos, na GrãB retanha, os policiais, a alfândega e o serviço secreto podem utilizar-se de arquivos de comunicação de dados de alguns meses, independentemente de permissão judicial, com base na Regulação do Poder de Investigação (R egulation of Investigatory Powers). B élgica, Dinamarca e França dispõem de regulamentos similares. 0 legislador espanhol examina um projeto de lei que prevê um local determinado de armazenamento por um ano (cf. Hünter, 2002, p. V 2/11). Na A lemanha, os dados precisam ser apagados, no máximo, após seis meses do envio pelos provedores, por razões de proteção. $\mathrm{Na}$ realidade, permanecem nos arquivos por mais tempo. A conseqüência de medidas mais amplas seria uma sociedade em que o Estado poderia, a qualquer momento, levantar os dados dos seus cidadãos além dos campos de comunicação.

\subsection{Limites e desvantagens}

As possibilidades de vigilância das novas tecnologias de comunicação, por parte das autoridades alemãs, são tão amplas que é espantoso quão pouco os êxitos logrados na luta contra a criminalidade são publicamente conhecidos. Nos
Estados U nidos, já há muitos anos são vigiados faxes, conversas telefônicas e e-mails pelo mundo todo com o sistema de espionagem Echel on (cf. German, 1998, p. 193-202).

Pelo menos quanto à Internet, resta um esclarecimento: quando se faz uma averiguação preventiva, a Internet oferece inumeráveis possibilidades de vigilância para filtrar terroristas dentre uma grande massa de internautas pacíficos, ou para descobrir preparativos para novos ataques.

Quando os computadores do FBI procuram por textos suspeitos nos e-mails com a ajuda de palavras-chave dadas, esse sistema deixa-se burlar facilmente por meio de códigos e cifras. A utilização de técnicas criptográficas pelo crime organizado, por terroristas e pelo próprio serviço secreto já é habitual há muito tempo. A té as demandas de muitos políticos, que desconhecem as possibilidades do software, pela proibição da utilização de técnicas criptográficas efetivas não resolvem o problema da comunicação conspiradora pela Internet. Por fim, em todos os procedimentos, os textos suspeitos precisam ser lidos e analisados, com demorada atenção, depois de filtrados de uma grande quantidade de dados. Para tal, deve-se dominar, além do inglês, também o árabe, o dari, o pachto e outros dial etos regionais e locais do Oriente Médio.

A vigilância mais acirrada sobre páginas suspeitas da I nternet também rende pouco. Há muitos outros lugares onde podem ser transmitidas mensagens secretas. Por exemplo, nas resenhas de um livro obscuro nas páginas da A mazon.com. Não se pode seguir as pegadas de um terrorista inteligente e organizado dessa maneira. A lém disso, há outras possibilidades utilizadas já há alguns anos por grupos criminosos organizados, como o envio de emails "anônimos" por meio de sistemas automáticos de anonimato, ou mesmo a transmissão de informações escondidas sob um quadro inocente com a ajuda da "estenografia" num arquivo enviado por e-mail (German, 2000, p. 83). Desde que sua comunicação por telefone via satéli ite passou a ser vigiada, Osama bin Laden utiliza walkie talkies. Descobriuse que, com o intuito de evitar o uso da Internet, as mensagens com instruções altamente 
cifradas são entregues em disquetes por mensageiros (cf. Horn, 2002, p. 20). Resulta daí que essa forma de vigilância sobre a comunicação local e global atinge cidadãos comuns, a economia, a ciência - e incomuns terroristas estúpidos (cf. Schrader, 2001, p. 23).

\section{Consider ações finais}

Infelizmente, os terroristas islâmicos conseguiram, indiretamente, com os ataques terroristas de 11 de setembro, prejudicar 0 impulso do espírito civilizador do 0 cidente. Os novos pacotes de segurança dos Estados $U$ nidos e da A lemanha mostram claras tendências na direção de um Estado de vigilância e do desmantel amento dos direitos de liberdade e de cidadania. 0 Estado de direito ameaça degenerar em um Estado preventivo, em que cada cidadão - ainda que sem suspeita concreta pode ser enquadrado por consideráveis medidas de segurança. A s experiências dos últimos meses mostram como se tornaram importantes nessa situação o Poder J udiciário, a imprensa e as organizações não-governamentais para a manutenção da democracia nesses países.

A maioria da população desconhece as conseqüências das novas políticas de segurança para os direitos dos cidadãos. Na verdade, vale o princípio do direito que diz que um direito fundamental só pode ser limitado por uma lei geral (Allgemeines G esetz) e não por uma lei casuísta (E inzelfallgesetz). M uitos, todavia, acreditam que as novas leis de segurança valem somente para árabes e terroristas putativos. N os Estados Unidos, os duvidosos métodos de averiguação foram sancionados pel o presidente, cuja afirmação "a A mérica encontra-se numa guerra" levou também a maioria da população a aceitá-los. A classe média americana imagina até coisas mais radicais quanto ao que deve acontecer com os terroristas. Os ressentimentos contra árabes e estrangeiros fortaleceram-se claramente também na Europa.

U $m$ ano após os ataques, não é publicamente conhecido o êxito das buscas sistemáticas, que poderia justificar as restrições dos direitos de liberdade. As violações dos princípios do Estado de direito e dos direitos da população evidenciam antes, nos Estados
Unidos, o desamparo dos investigadores. As mais variadas panes e falhas das autoridades de vigilância e o déficit de segurança dos aeroportos americanos antes dos ataques indicam que a necessária luta contra 0 terrorismo não pode ser ganha primordial mente por meio do recrudescimento das leis e pela vigilância sobre a comunicação mundial. Para a luta contra o terrorismo de B in Laden, fazse necessário muito mais o uso de silenciosos e tradicionais métodos policiais e de inteligência, além de infiltração, suborno de agentes e outros elementos nada agradáveis. 0 mais importante é um trabalho conjunto com 0 serviço de inteligência dos países do Oriente Próximo, que entendem melhor sua freguesia.

Infelizmente, com respeito à onda de solidariedade internacional que se seguiu aos ataques de 11 de setembro, o prestígio internacional dos Estados U nidos diminuiu em razão dos caminhos tomados pelo presidente B ush na política interna e externa. 0 país freqüentemente admi rável - que, de acordo com G eorg J ellinek, marcou o início da idéia moderna dos direitos humanos e da cidadania com o famoso texto do Bill of Rights da Virgínia, em 1776 - encontrase hoje governado por um presidente que se notabiliza pelo uso da prerrogativa de poder. Como definiu J ohn Locke, já em 1689: “Este poder de agir de acordo com a discrição em favor do bem público, sem a prescrição da lei e muitas vezes contra ela, é o que se chama prerrogativa" (Locke, 1974, p. 124).

0 rumo da política externa do governo $\mathrm{W}$. $B$ ush tem sido mesmo comentado com reservas em muitas partes do mundo. Para os europeus ocidentais, a incompreensível recusa em participar da Convenção A ntitortura ou do Tribunal Penal Internacional só consegue ser superada pela retórica historicamente míope do presidente. George W. B ush justifica assim 0 início do bombardeio do A feganistão: "Todo governo que financiar foras-da-lei e assassinos de inocentes terá se tornado el e próprio também um fora-da-lei e homicida. E ele terá tomado aquela rota solitária do seu próprio risco" (M onbiot, 2001/2002, p. 19). 0 presidente americano disse claramente: "todo governo". 
No continente americano, um país é conhecido por, nos últimos 50 anos de ditaduras militares, ter formado mais de sessenta mil soldados latino-americanos nas suas academias militares, cujos manuais continham instruções para chantagens, prisão de familiares, torturas e execuções. Contam-se entre as vítimas dos regimes autoritários latino-americanos milhares de pessoas inocentes. Assim, a conhecida política das meias verdades e realidades (os double standards) obteve por meio do governo W. B ush uma nova variável.

Abstract: The essay intends to expose and analyse the
new security laws anti-terror in USA and Europe. The
efficacy of the new security laws after "11. September"
and the consequences for the electronic comminication.
The use of a spy system and the effects by terrorists
attadks' sequels upon the west civilization' s push. The
text still argues about the advantages and the disadvantages
from these "Patrioct Acts" and what considerations can
been made about the formation on a watchfulness' state
and the pull down of rights liberty and citizenship.

K ey-words: laws of searity anti-terror; watchfulness and rights of sigil in Intemet; terrorism.

\section{Referências}

BITTNER, J ochen. Löcher im D atennetz. In: Die Zeit, n. 12, 14 de março de 2002, p. 4.

BORCHERS, Detlef. Ein zahnloser Fleischfresser. In: Süddeutsche Zeitung, 18 de setembro de 2001, p. 14. BÜRGERRECHTE; POLIZEI. Überwachung neuer Kommunikationstechnologien, Cilip 71, n. 1/2002, Berlim.

FL OTTAU, Heiko: Rache statt Religion; SCHM ITZ, Thorsten. Erkundungsmission im Gefängnis. In: Süddeutsche Zeitung, $1^{\circ}$ de agosto de 2002, p. 2.

FUNK, A lbrecht. US-Terrorismusbekämpfung und "N ationale Sicherheit". In: Bügerrechte $\&$ P olizei. Terrorismusbekämpfung - alte und neue Irrwege, Cilip 70, n. 3/2001, p. 63-70.

GERMAN, Christiano. Europa und die globale Informationsgesellschaft. In: GEL LNER, Winand; KORFF, Fritz von ( $\mathrm{Ed}$.), Demokratie und Internet, Baden-B aden 1998, p. 193-202.

. 0 caminho do Brasil rumo à era da informação. São Paulo: Fundação Konrad A denauer, 2000, p. 83.
Online - offline: informação e democracia na sociedade de informação. In: GUIMARÃES, César; JUNIOR, Chico (O rgs.). Informação \& democracia. Rio de J aneiro: XXXX, 2000, p. 113$136,130$.

HENNIG, Eike. Grundrechte. In: GÖRLITZ, A lex (Ed.). $H$ andlexikon zur Politikwissenschaft, $M$ unique 1970, p. 141-145, p. 142/143, e M enschenrechte. In: Staatslexikon, terceiro tomo, 7. ed., F reiburg, 1988, p.1104-1118, 1116.

HERZINGER, Richard. Was für den Westen zählt, ou: Sind amerikanische Werte auch unsere Werte? In: Aus Politik und Zeitgeschichte, 3 de maio 2002, B 18/2002, p. 3-6, 4.

HORN , Eva. U nheimliches Versagen. In: Süddeutsche Zeitung, 21 de setembro de 2002, p. 20.

HÜRTER, Tobias. Von der Leine gelassen. In: Süddeutsche Zeitung, 18 de junho de 2002, p. V 2/14.

. Der GroßeB ruder wird größer. In: Süddeutsche Zeitung, 25 de junho de 2002, p. V 2/11.

KERSCHER, Helmut; W IRTZ, Christiane. Limbach warnt vor Übereifer des Staates. In: Süddeutsche Zeitung, 11 e 12 de maio de 2002, p. 5.

K LINGST, M artin. Datenschutz=Terroristenschutz? Unsinn! (Conversa com Spiros Simitis). In: Die Zeit, 4 de Outubro de 2001, n. 41, p. 5.

Verschlüsselte Botschaften, G espräch mit Bundesinnenminister Otto Schily. In: D ie Zeit, 25 de abril de 2002, n. 18, p. 10

KOYDL, Wolfgang. Ein einziges, dauerhaftes $M$ inisterium. In: Süddeutsche Zeitung, 8/9 de junho de $2002 a$, p. 5.

. Bush stellt neue Sicherheits-Strategie vor. In: Süddeutsche Zeitung, 17 de julho de 2002b, p. 8.

Einsperren und den Schlüssel wegwerfen. In: Süddeutsche Zeitung, 17 de junho de 2002c, p. 3.

Pakt mit dem Taliban. In: Süddeutsche Zeitung, 17 de julho de 2002d, p. 8.

LEY ENDECKER, Hans. K onspiratives Schattenboxen. In: Süddeutsche Zeitung, 16 de abril de 2002, p. 2.

LOCKE, John. Über die Regierung (The second treatise of government). Com prefácio de Peter Cornelius M ayer-Tasch. Stuttgart, 1974, p.124, capítulo XIV, art. 160.

M ARKUS, Clemens.US-K ongress ermittelt gegen CIA und FBI. In: Süddeutsche Zeitung, 5 jun. 2002, p. 8.

M ONBIOT, George. B ackyard Terrorism. Washington has been training terrorists at a Georgia base for 
years, and is still at it. In: Rethinking Schools. An U rban Educational J ournal, Inverno 2001/2002, v. 16, n. 2, p. 19.

PRA NTL. Harmonie, unumstritten. In: D ie Zeit, 4 de outubro de 2001, n. 41, p. 5.

. Heribert: Schläfer im B in-Laden-Hemd. In: Süddeutsche Zeitung, 23 de abril de 2002, p. 4.
SCHNUR, Roman (Ed.). Zur G eschichte der Erklärung der M enschenrechte. Darmstadt, 1964.

SCHRADER, Christopher. Maßnahmen gegen Dumme. In: Süddeutsche Zeitung, 21 de setembro de 2001, p. 23.

RECEBIDO EM DEZEMBRO DE 2002

A PROVADO EM JULHO DE 2003 